\title{
Delayed Intracerebral Hemorrhage after Placement of a Ventriculoperitoneal Shunt in a Case of Hydrocephalus: A Rare Case Report and Review of Literature
}

\author{
Siddartha Reddy Musali ${ }^{1}$ Srikrishnaditya Manne ${ }^{1} \quad$ Hemant K. Beniwal ${ }^{1} \quad$ Nagarjuna Butkuri ${ }^{1}$ \\ Prakash Rao Gollapudi ${ }^{1}$ Pratap Kumar Nandigama ${ }^{1}$
}

\author{
${ }^{1}$ Department Of Neurosurgery, Gandhi Medical College and \\ Hospital, Secunderabad, Telangana, India
}

\begin{abstract}
Address for correspondence Srikrishnaditya Manne, MS, 12-13$677 / 113$, Street No. 1, Lane No. 2, Kimtee Colony, Tarnaka, Secunderabad 500017, Telangana, India (e-mail: aditya.6356@gmail.com).
\end{abstract}

\begin{abstract}
Keywords

- delayed

- intracerebral hemorrhage

- ventriculoperitoneal shunt

Ventriculoperitoneal (VP) shunt is a frequently performed operation to achieve cerebrospinal fluid (CSF) diversion but is associated with many complications. Postoperative delayed intracerebral hemorrhage is a kind of rare but catastrophic complication of a VP shunt which questions the survival of a seemingly recovered patient. Here, we present one such case where the patient presented to casualty in altered sensorium and with a history of vomiting. On examination, the Glasgow Coma Scale (GCS) score was E2V1M3; pupils were middilated but reactive. Computerized tomography of the brain showed ventriculomegaly and hydrocephalus, and an emergency VP shunt was done. There was an initial phase of good recovery followed by sudden loss consciousness, vomiting, and a fall in the GCS scores on postoperative day 7. Computed tomography showed an intracerebral hematoma along the shunt track and an intraventricular bleed. The presumed cause for this occurrence is a deranged coagulation profile.
\end{abstract}

\section{Introduction}

Ventriculoperitoneal (VP) shunt is a frequently performed neurosurgical procedure and is almost a standard first-line treatment for hydrocephalus. It is safely done even in infants. Usual postoperative complications are shunt block, shunt malfunction, infection, migrating catheter, seizures, and subdural hematoma. ${ }^{1}$ Very rarely, we come across intracerebral hematoma as a complication, and a delayed presentation of the same is even rarer. Small amounts of blood are frequently seen on imaging in the ventricle or in the parenchyma along the catheter path but clinically significant hemorrhage is rare. ${ }^{2,3}$ This rare occurrence of intracerebral bleed or intraventricular hemorrhage after placing a VP shunt has been reported in a few patients. In 1985, Matsumura reported the first case of delayed intracerebral hemorrhage after VP shunting in a 17-year-old male on postoperative day $7 .{ }^{4}$
Fukamachi et al stated in his report that this phenomenon usually occurs immediately after surgery. ${ }^{5}$ In several large series reviewing the complications of VP, the authors do not mention intracerebral hemorrhage. ${ }^{6,7}$ Bleeding secondary to ventricular puncture may be detected on imaging studies. The incidence in published reports varies from 0.3 to $4 \%$.

Here, we report a rare case of intracerebral and intraventricular hemorrhage who was admitted with hydrocephalus and underwent VP shunt on an emergency basis and had an intracerebral hemorrhage during the postoperative period.

\section{Case Report}

A 56-year-old female was brought to the emergency department by her family members in a state of altered sensorium, difficulty in walking, and inability to accept feeds for 
5 days. She had a history of a headache for the past 2 weeks associated with vomiting and fever. On clinical examination, her Glasgow Coma Scale (GCS) score was E2V1M3. Pupils were middilated but reactive to light. On ophthalmoscopy, papilledema was noted and signs of raised intracranial tension were established. On a computerized tomography scan, hydrocephalus was established (-Fig. 1). Consent for emergency cerebrospinal fluid (CSF) diversion was obtained, and a VP shunt was done. The CSF was sent for analysis. The procedure was completed uneventfully, and postoperative recovery was good. The GCS score improved, and the patient started obeying commands from postoperative day 1 itself. A postoperative scan of the patient was taken on postoperative day 2 , the shunt was noted in situ, and moderate resolution of the hydrocephalus was noted (-Fig. 2). The patient was doing well, and the CSF analysis results were positive for acid-fast bacilli. The patient was started on antituberculous treatment and was being planned for discharge. On postoperative day 7, there was a sudden fall in the GCS score. The patient had a sudden loss of consciousness with vomiting, and GCS score at that moment was E2V1M3. A computerized tomography scan of the brain was taken, and there was an intracerebral hematoma noted around the shunt track along with intraventricular hemorrhage (-Fig. 3). In view of poor GCS, the patient was intubated, and ventilator support was given. A complete coagulation profile including

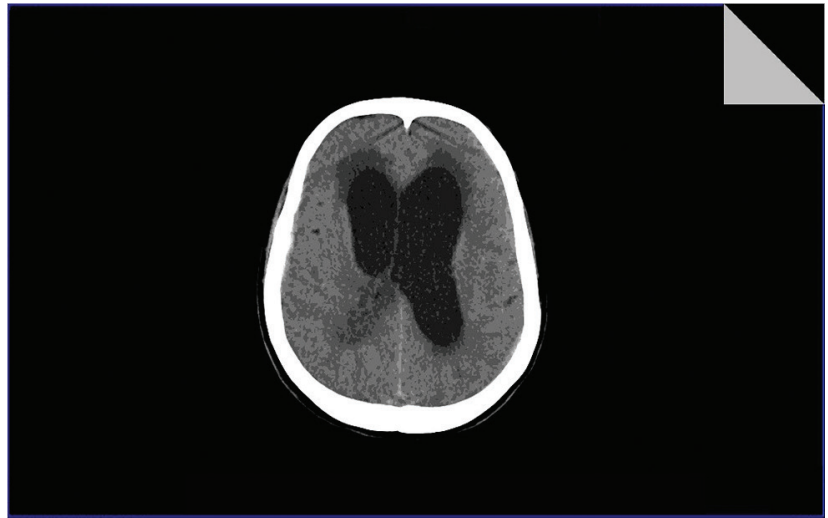

Fig. 1 First computerized tomography scan on admission showing hydrocephalus.

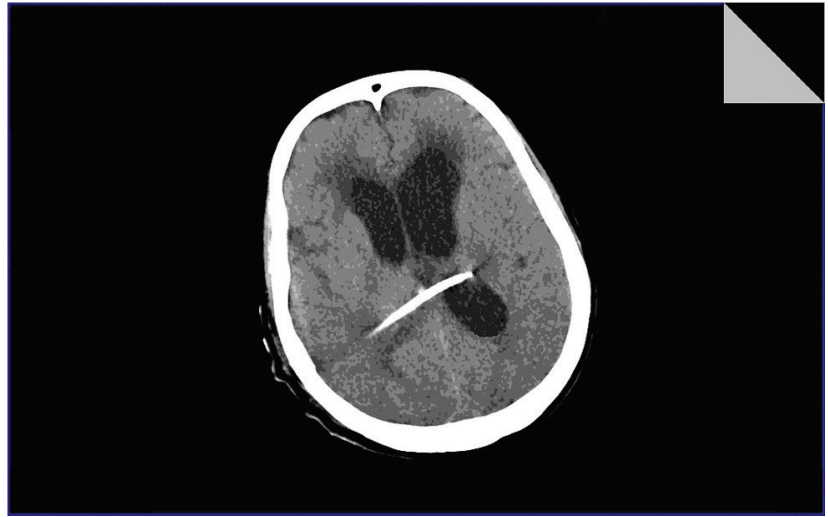

Fig. 2 Second postoperative day scan showing shunt in situ.

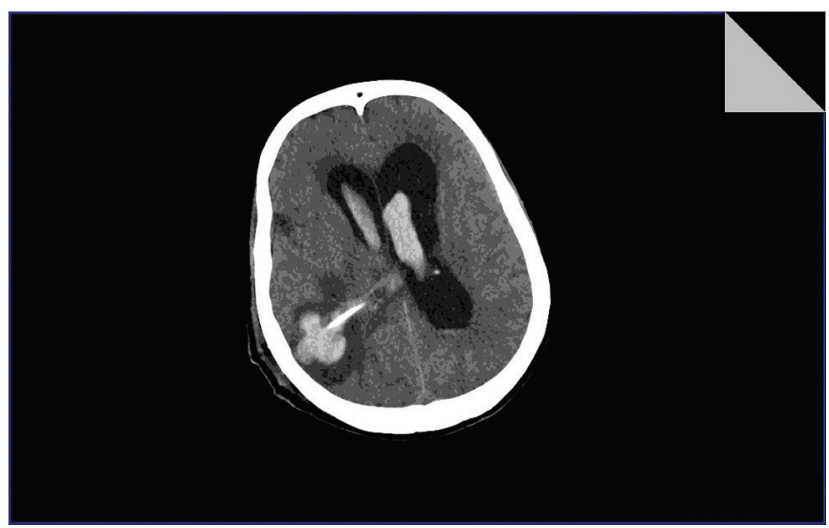

Fig. 3 Seventh postoperative day scan showing intracerebral hemorrhage along the shunt track and intraventricular bleed.

prothrombin time and the international normalized ratio (INR) was done. Prothrombin time (PT) was found to be prolonged (24 seconds), and INR was raised (2.1). On probing, the attendants gave a history that the patient was a chronic alcoholic and consumes alcohol and toddy on a daily basis. Within the next 2 hours, she succumbed in spite of adequate resuscitation efforts. This is a rare scenario where an intracerebral bleed along with intraventricular bleed led to the death of the patient after an initial period of good recovery, and postoperative day 2 computerized tomography scan shows no evidence of a bleed.

\section{Discussion}

VP shunt is a straightforward and most commonly performed emergency neurosurgical procedure, which is rarely associated with complications which, has an onset within a few days in the postprocedural period. The most commonly encountered complication is that of a shunt malfunction or shunt blockade which is more or less acceptable all around the globe to neurosurgeons and is frequently explained to the patient and attendants about this complication, so that it should not warrant them to decline the procedure which in turn can be afflictive to the patient at the moment. Shunt malfunctions can be reasoned with at a later date with shunt removal followed by a period of observation and a revision shunt procedure if the need arises. What most neurosurgeons do not come across and which is an unforeseen complication both for the surgeon and for the patient is the occurrence of an intracerebral hematoma, more so along with intraventricular hemorrhage. In several large series, reviewing the complications of this procedure, the authors do not mention intracerebral hemorrhage. We can find some reports of such a complication in which the hemorrhage occurred directly after the operative procedure (- Table 1). ${ }^{3,7,8}$ Several mechanisms whereby intracerebral hemorrhage can occur after ventricular cannulation can be described ${ }^{9}$ in - Table 2 as follows: a coexistent bleeding disorder, shunt-induced disseminated intravascular coagulation, disruption of an intracerebral vessel by the catheter, hemorrhage into an intracerebral tumor, hemorrhage from an occult vascular malformation, 
Table 1 Previous similar studies/case reports

\begin{tabular}{|c|c|c|c|}
\hline Authors & $\begin{array}{l}\text { Number } \\
\text { of cases }\end{array}$ & $\begin{array}{l}\text { Year of } \\
\text { publication }\end{array}$ & $\begin{array}{l}\text { Postoperative } \\
\text { day }\end{array}$ \\
\hline Zhou et al ${ }^{10}$ & 2 & 2012 & $\begin{array}{l}\text { Case } 1: \text { day } 5 \\
\text { Case } 2: \text { day } 3\end{array}$ \\
\hline Martin H. Savitz ${ }^{11}$ & $\begin{array}{l}5 \text { (study } \\
\text { of } 125 \\
\text { cases over } \\
24 \text { years) }\end{array}$ & 1999 & - \\
\hline Alcázar et al ${ }^{12}$ & 1 & 2007 & Day 6 \\
\hline Zhao et al $^{13}$ & 1 & 2014 & Day 3 \\
\hline Kouichi Misaki ${ }^{14}$ & 4 & 2009 & $\begin{array}{l}\text { Case } 1: 4 \mathrm{~h} \\
\text { Case } 2: 2 \mathrm{~d} \\
\text { Case } 3: 7 \mathrm{~d} \\
\text { Case } 4: 13 \mathrm{~d}\end{array}$ \\
\hline
\end{tabular}

Table 2 Various causes of delayed intracerebral hemorrhage after ventriculoperitoneal shunt and review of literature

\begin{tabular}{|l|l|}
\hline Mechanism & Proposed by \\
\hline $\begin{array}{l}\text { Increased intracranial venous pressure } \\
\text { produced by Valsalva's effect }\end{array}$ & Matsumura et al ${ }^{4}$ \\
\hline $\begin{array}{l}\text { Mechanical disruption of intravascular } \\
\text { vessel by catheter }\end{array}$ & Multiple authors \\
\hline Coagulation disorder & Multiple authors \\
\hline $\begin{array}{l}\text { Hemorrhage from an occult intravas- } \\
\text { cular malformation or an intracerebral } \\
\text { tumor }\end{array}$ & Multiple authors \\
\hline $\begin{array}{l}\text { Head trauma occurring shortly after VP } \\
\text { shunt placement }\end{array}$ & Multiple authors \\
\hline $\begin{array}{l}\text { Normal pulsations of the CSF transmit } \\
\text { to the ventricular catheter that helps } \\
\text { the catheter to erode a blood vessel and } \\
\text { cause ICH }\end{array}$ & Multiple authors \\
\hline $\begin{array}{l}\text { Decrease of tamponade forces second- } \\
\text { ary to the sudden reduction of CSF pres- } \\
\text { sure after placement of the VP shunt }\end{array}$ & Mascalchi et al ${ }^{15}$ \\
\hline VP shunt-induced DIC & Khandelal et al ${ }^{16}$ \\
\hline
\end{tabular}

Abbreviations: CSF, cerebrospinal fluid; DIC, disseminated coagulation; ICH, intracerebral hemorrhage; VP, ventriculoperitoneal.

and head trauma occurring shortly after shunt placement. Hemorrhaging may be caused by multiple attempts at perforation of the ventricles, puncture of the choroid plexus, or improper placement of the tubing within the parenchyma of the brain. Ventricular collapse after tube insertion might induce tighter contact between the catheter and vasculature and lead to subsequent erosion of the vasculature. ${ }^{10}$ Small amounts of bleed were noticed within the ventricles in $10 \%$ of cases in the Palmieri's series, and even less frequently, small pools of blood were noted under the ependyma next to the catheter tip or along its path in the parenchyma. Snow reported an incidence of moderate hemorrhage after ventricular shunting procedures of $0.3 \%$ (3-5 $\mathrm{cm}$ in maximal diameter). Udvarhelyi et al reported two cases of intracerebral hematoma after VP shunting among 55 cases of normal pressure hydrocephalus.

In our particular case, the cause of bleed can be a deranged coagulation profile. The patient hails from a remote place where the consumption of toddy and alcohol among females is common and not a social taboo. The initial postoperative scan done 2 days after the surgery showed no evidence of bleed, and hence, it poses us with an important question,

Can a deranged coagulation profile be a causative factor for delayed intracerebral hematoma after a VP shunt and not cause intraoperative or immediate postoperative bleed? The answer to this question might elude us, but it establishes a fact that even on emergency basis coagulation profile should be stressed upon so that adequate measure like factors replacement can be considered thus avoiding such complications.

\section{Conclusion}

The most common complications associated with VP shunt are shunt malfunction, migration of the catheters, kinking of the shunt tube, subdural hematomas, seizures, etc. Intracerebral hematoma along with intraventricular hemorrhage is a rare occurrence in the postoperative period. Delayed occurrence of the same is even rarer. Here, we presented a case which we encountered and went ahead with a VP shunt. There was a good recovery postoperatively which was followed by sudden deterioration in the late postoperative period, while the patient was being considered for discharge. The coagulation profile of the patient was deranged, but we could not asses for the same in the emergency setup. The review of literature establishes the fact that this occurrence is certainly a complication rather than an accident and should always be considered in patients who show improvement followed by deterioration in the postoperative period. Overall, we can say that deranged coagulation profile may be a cause for delayed intracerebral hemorrhage in a patient with VP shunt whose early postoperative scan showed signs of improvement and no bleed.

\section{Conflict of Interest}

None declared.

\section{References}

1 Wu Y, Green NL, Wrensch MR, Zhao S, Gupta N. Ventriculoperitoneal shunt complications in California: 1990 to 2000. Neurosurgery 2007;61(3):557-562, discussion 562-563

2 Ivan LP, Choo SH, Ventureyra EC. Complications of ventriculoatrial and ventriculoperitoneal shunts in a new children's hospital. Can J Surg 1980;23(6):566-568

3 Palmieri A, Pasquini U, Menichelli F, Salvolini U. Cerebral damage following ventricular shunt for infantile hydrocephalus evaluated by computed tomography. Neuroradiology 1981;21(1):33-35

4 Matsumura A, Shinohara A, Munekata K, Maki Y. Delayed intracerebral hemorrhage after ventriculoperitoneal shunt. Surg Neurol 1985;24(5):503-506 
5 Fukamachi A, Koizumi H, Nukui H. Postoperative intracerebral hemorrhages: a survey of computed tomographic findings after 1074 intracranial operations. Surg Neurol 1985;23(6):575-580

6 Raimondi AJ, Robinson JS, Kuwawura K. Complications of ventriculo-peritoneal shunting and a critical comparison of the three-piece and one-piece systems. Childs. Brain 1977;3(6):321-342

7 Sayers MP. Shunt complications. Clin Neurosurg 1976;23: 393-400

8 Udvarhelyi GB, Wood JH, James AE Jr., Bartelt D. Results and complications in 55 shunted patients with normal pressure hydrocephalus. Surg Neurol 1975;3(5):271-275

9 Snow RB, Zimmerman RD, Devinsky O. Delayed intracerebral hemorrhage after ventriculoperitoneal shunting. Neurosurgery 1986;19(2):305-307

10 Zhou F, Liu Q Ying G, Zhu X. Delayed intracerebral hemorrhage secondary to ventriculoperitoneal shunt: two case reports and a literature review. Int J Med Sci 2012;9(1):65-67
11 Savitz MH, Bobroff LM. Low incidence of delayed intracerebral hemorrhage secondary to ventriculoperitoneal shunt insertion. J Neurosurg. doi: 10.3171/jns.1999.91.1.0032

12 Alcazar L, Alfaro R, Tamarit M, et al. Delayed intracerebral hemorrhage after ventriculoperitoneal shunt insertion, Case report and literature review. Neurocirugia 2007;18:128-133

13 Zhao J, Chen Y, Yang K, Hu X. A case of repeated intracerebral hemorrhages secondary to ventriculoperitoneal shunt. Interdiscip Neurosurg 2015;2(1):48-50

14 Misaki K, Uchiyama N, Hayashi Y, Hamada J. Intracerebral hemorrhage secondary to ventriculoperitoneal shunt insertion-four case reports. Neurol Med Chir (Tokyo). 2010 Jan;50(1):76-79

15 Mascalchi M, Delayed intracerebral hemorrhage after CSF shunt for communicating "normal-pressure" hydrocephalus. Case report. Ital J Neurol Sci 1991;12:109-112

16 Khandelwal A, Singh PK, Basheer N, et al. Delayed bilateral thalamic bleeding post ventriculoperitoneal shunt. Childs Nerv Syst 2011;27:1025-1027 